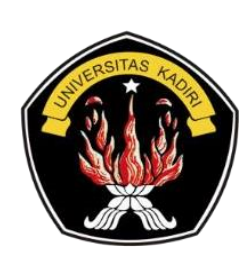

Tersedia secara online di http://ojs.unik-kediri.ac.id/index.php/jatiunik/issue/view/76

\title{
Analisis Coal Plugging Atau Penyumbatan Batu Bara Pada Mesin Coal Feeder Unit 1-4 Dengan Metode FTA (Fault Tree Analysis) Di PT. ABZ
}

\author{
Muhammad Bob Anthony ${ }^{* 1}$ \\ ${ }^{1}$ Program Studi Teknik Industri, Fakultas Teknik, Universitas Serang Raya \\ Email: tonipbmti@gmail.com
}

\begin{tabular}{|c|}
\hline InformasiArtikel \\
\hline $\begin{array}{l}\text { Riwayat Artikel : } \\
\text { Received : } 17-\text { Februari }-2020 \\
\text { Revised : } 23-\text { Maret }-2020 \\
\text { Accepted : } 17-\text { April - } 2020\end{array}$ \\
\hline
\end{tabular}

Kata kunci :

Coal Blockage

Coal Feeder

Fault Tree Analysis
Untuk melakukan sitasi pada penelitian ini dengan format : A. Y. Kristanto and R. Rumita, "Analisis Penyebab Cacat Kain Dengan Menggunakan Metode Failure Mode and Effect Analysis (Fmea) Dan Fault Tree Analysis (Fta)," vol. 5, no. 1, pp. 1-8, 2016.

\begin{abstract}
PT. ABZ is one of the big companies that runs its main business in the field of power generation in Indonesia. The company is experiencing problems in one of its equipment, namely coal feeder units 1-4 which often occurs coal plugging or coal blockage. Coal feeder is one of the main equipment that serves to regulate the amount of coal entering the pulverizer. This study aims to determine the root cause of problems from coal plugging or coal obstruction in coal feeder equipment at PT. ABZ using the FTA (Fault Tree Analysis) Method and provides a proposed improvement with the $5 \mathrm{~W}+1 \mathrm{H}$ Method (what, why, who, when, where and how). Based on the analysis using FTA, it was found that the cause of coal plugging or blockage that occurs in coal feeder machines is due to contamination of the coal used, low calorific value of coal, the machine operates continuously, the machine is old, lack of control from the workers and coal wet when you want to use. Proposed improvements have been made and one of them is by separating wet coal from dry coal automatically using a coal online analyzer.
\end{abstract}

\section{A b s t r a k}

PT. ABZ merupakan salah satu perusahaan besar yang menjalankan bisnis utamanya dibidang pembangkit tenaga listrik di Indonesia. Perusahaan ini mengalami permasalahan di salah satu peralatannya yaitu coal feeder unit 1-4 yang sering terjadi coal plugging atau penyumbatan batubara. Coal feeder merupakan salah satu peralatan utama yang berfungsi untuk mengatur jumlah batubara yang masuk ke pulverizer. Penelitian ini bertujuan untuk mengetahui akar penyebab masalah dari gangguan coal plugging atau peyumbatan batu bara di peralatan coal feeder di PT. ABZ dengan menggunakan Metode FTA (Fault Tree Analysis) dan memberikan usulan perbaikan dengan Metode $5 \mathrm{~W}+1 \mathrm{H}$ (what, why, who, when, wheredan how). Berdasarkan analisa menggunakan FTA, didapatkan bahwa penyebab coal plugging atau penyumbatan yang terjadi pada mesin coal feeder adalah dikarenakan adanya kontaminasi pada batubara yang digunakan, nilai kalori batubara yang rendah, mesin beroperasi secara terus menerus, mesin sudah tua, kurang nya kontrol dari pihak pekerja 
dan batu bara basah saat akan digunakan. Usulan perbaikan telah dibuat dan salah satunya adalah dengan cara memisahkan batu bara basah dengan batu bara yang kering secara otomatis menggunakan alatcoal online analyzer.

\section{Pendahuluan}

PT. ABZ merupakan salah satu perusahaan besar yang menjalankan bisnis utamanya dibidang pembangkit tenaga listrik di Indonesia. Perusahaan ini mengalami permasalahan di salah satu peralatannya yaitu coal feederunit 1-4 yang sering terjadi coal plugging atau penyumbatan batubara [1].Coal feeder berfungsi untuk mengatur jumlah batubara yang masuk ke pulverizer. Jumlah batubara yang masuk ke pulverizer berubah-ubah sesuai dengan beban unit pembangkit [2]. Oleh karena itu, outputcoal feeder pun berubah-ubah sesuai kebutuhannya.Pengaturan output coal feederdapat dilakukan dengan dua cara yaitu dengan motor penggerak yang putarannya dapat diatur (variable speedmotor) atau dengan motor putaran tetap yang dilengkapi dengan variable speed drive[3].
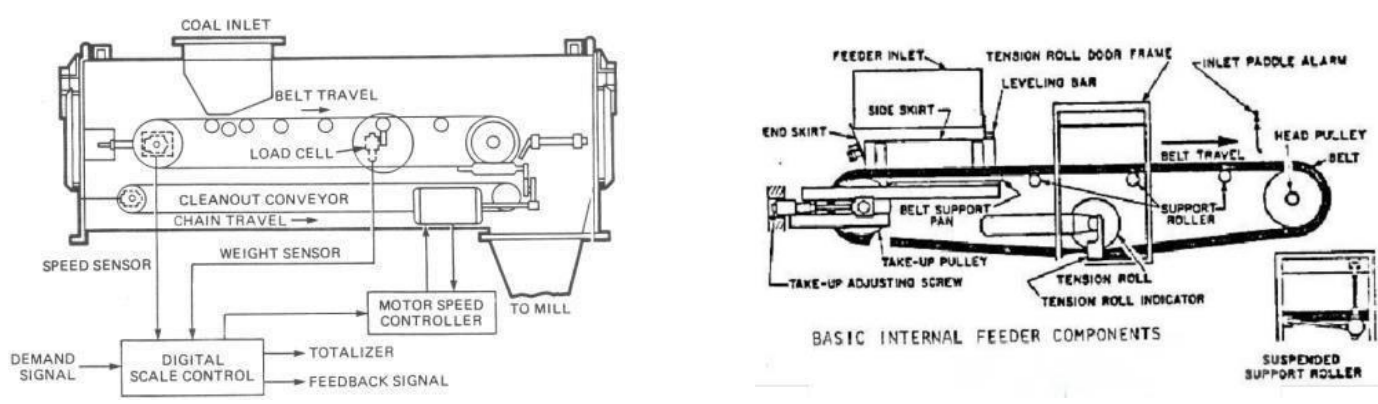

Gambar 1. Cool Feeder dan Komponen Dalam

Penyaluran batubara di energi utama PT. ABZ menggunakan hopper sebagai stok persediaan batubara yang ada. Hopper yang digunakan merupakan jenis hopper bawah tanah dan terbuka yang berada di coal yard. Batubara yang berada pada hopper disalurkan menuju unit-unit melewati beberapa belt conveyor dan junction house menuju coal feeder.Kendala yang dihadapi pada saat menggunakan batubara dari hopper adalah kualitas batubaranya yang tidak terjaga moisture-nya sehingga berdampak pada terganggunya proses penyaluran batubara menuju ruang bakar atau boiler dikarenakan adanya plugging di coal feeder.

Kualitas batubara sangat mempengaruhi kinerja boiler dari berbagai sisi. Pengukuran kualitas batubara menjadi aktivitas yang sangat penting dalam menjaga keberlangsungan operasi coalfeeder untuk ke boiler[4]-[6]. Pengukuran dapat dilakukan mulai saat bongkar muatan batubara di dermaga hingga saat batubara mengalir di dalam coal feeder menuju boiler. Pengukuran kualitas tidak hanya didasarkan pada satu parameter saja akan tetapi harus dilakukan secara komprehensif. Kegagalan di dalam boiler tidak hanya terpengaruh oleh operasi yang terjadi di dalam boiler itu, tetapi juga oleh operasi-operasi pendukung lainnya misalnya penanganan batubara selama pengaliran dari stock yard hingga masuk ke dalam boiler [7]. Berdasarkan laporan pada gangguan dan performa unit 1-7 di PT. ABZ didapatkan bahwa gangguan yang berasal dari coal plugging berdampak cukup signifikan yaitu sebagai berikut : 
a. Gangguan plugging mengakibatkan kehilangan kesempatan produksi secara optimal.

b. Gangguan plugging sering terjadi pada pasokan batubara untuk unit 1-4.

c. Heat rate yang terus meningkat didominasi karena ketidak optimalan penyaluran batu bara ke masing - masing unit.

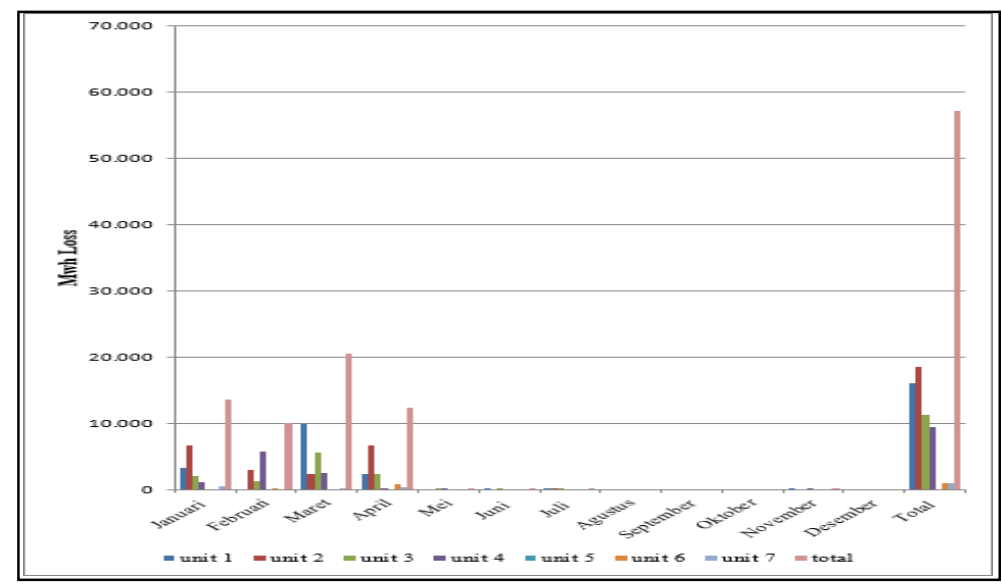

Gambar 2. Data Plugging tahun 2018 Unit 1-7

Penyumbatan batubara atau coal plugging ini menyebabkan kegiatan operasional di PT. ABZ menjadi tidak efisien dan kualitas produk menjadi tidak sesuai dengan standar kualitas yang ditetapkan. Tujuan penelitian ini adalah untukmengetahui akar penyebab masalah darigangguan coal pluggingatau peyumbatan batubaradi peralatan coal feeder di PT. ABZ dengan menggunakan Metode FTA (Fault Tree Analysis) dan memberikan usulan perbaikan dengan Metode 5W $+1 \mathrm{H}$ (what, why, who, when, wheredan how)agar kegiatan operasional di PT. ABZ menjadi efisien dan efektif sehingga kualitas produk sesuai dengan standar kualitas yang ditetapkan[8]-[11].

Penggunaan FTA dapat digunakan untuk mengidentifikasi beberapa kesalahan dalam kemampuan diagnostik kesalahan sistem. Disisi lain juga untuk merepresentasikan penyebab masalah serta sebagai pengenalan pemeriksaan konsistensi dengan informasi yang diberikan untuk menghasilkan daftar yang akurat dari semua penyebab potensial dari status sistem saat ini. Fungsi dari pembentukan pohon FTA sebagai langkah pemeriksaan konsistensi menggunakan informasi dari semua kegiatan observasi untuk menghasilkan daftar penyebab potensial [10]. Dalam hal ini, langkah penting dalam menentukan kemungkinan terjadinya peristiwa pemicu potensial, adalah menangani risiko, melakukan pendekatan probabilistik mungkin lebih disukai karena ketidakpastian signifikan yang terlibat dalam analisis berdasarkan pohon hieraki [11].

Diperlukan mengembangkan model pengoptimalan yang dapat meminimalkan risiko yang tidak diinginkan, karena dapat menyebabkan hal yang tidak berarti untuk perusahaan. Oleh sebab itu, analisis yang dilakukan akan berdampak pada suatu pola hirarki yang sudah disusun menggunakan FTA. Kerentanan titik permintaan dihitung dengan menggunakan analisis pohon kesalahan dan dimasukkan ke dalam model pengoptimalan secara inovatif dan menghasilkan perhitungan eksplisit [12].

Penggunaan FTA dapat digunakan sebagai penilaian jenis kecacatan dalam produk, kemudian sebagai identifikasi kegagalan proses yang ditinjau dari tingkat keparahan, 
penyebab yang terjadi serta dapat ditentukan rekomendasi perbaikan didalam rumusan masalah yang diangkat [13].

\section{Tinjauan Pustaka}

\subsection{Fault Tree Analysis}

FTA(Fault Tree Analysis) adalah metode analisaterhadap suatu kejadian yang tidak diinginkan yang disebut sebagai undesiredeventyang terjadi pada sistem dan sistem tersebut kemudian dianalisa dengan kondisi lingkungan dan operasional yang ada untuk menemukan semua cara yang mungkin terjadi mengarah pada terjadinya undesired event tersebut[14]-[16]. Analisa kegagalan sistem dengan metode FTA dibuat menggunakan pohon kegagalan atau fault tree dari suatu sistem yang dianalisa terlebih dahulu.Fault tree adalah model grafis dari kegagalan-kegagalan pada suatu sistem dan kombinasinya sehingga menghasilkan terjadinya undesired event[17]-[19]. Kegagalan yang ada pada sistem bisa dikarenakan kegagalan pada komponennya, kegagalan pada manusia yang mengoperasikannya(human eror) dan kejadiankejadian diluar sistem yang dapat mengarah pada terjadinya undesired event [20], [21]. Fault tree dibangun berdasarkan pada salah satu undersired event yang dapat terjadi pada sistem[22]-[25]

\subsection{Penyumbatan Batu Bara}

Pada jalur yang dilalui oleh batu bara diletakkan pada hoper yang akan dikumpulkan. Pengumpulan melalui vibrating screean yang dialirkan pada belt conveyor[26]. Kemudian ditujuan pada coal dan ditampung pada junction tower. Dalam hal ini, selalu ada kendala yaitu karena batu bara menyumbat coal. Penyumbaran tersebut karena ada faktor tertentu yang perlu dilakukan identifikasi secara mendalam[27].

\section{Metode Penelitian}

Penelitian ini dilakukan di PT. ABZ yang bergerak dibidang pembangkit tenaga listrik. Objek penelitian ini adalah peralatan coal feeder di PT. ABZ. Pengumpulan data dilakukan dengan dua cara yaitu studi pustaka dan observasi langsung ke lapangan melalui wawancara kepada pihak manajemen perusahaandan beberapa pekerja PT. ABZ selama enam bulan yaitu bulan juli sampai dengan desember 2019[28]. Batasan masalah yang digunakan dalam penelitian ini adalah tidak melakukan perhitungan Failure Mode and Effect Analysis sebagai upaya untuk mengetahui komponen yang kritis. Observasi yang dilakukan fokus pada sistem coal feeder dibagian coal plugging. Penelitian ini tidak melakukan perubahan data selama observasi yang dilakukan. Subyek dari penelitian ini adalah PT. ABZ sebagai tempat mencari informasi terkait dengan penelitian, sedangkan pada obyek penelitian ini adalah melakukan analisis menggunakan metode Fault Tree Analysis untuk mengetahui penyebab coal plugging. Penggunaan data penelitian berdasarkan jenisnya adalah kualitatif dan kuantitatif. Pada data kualitatif antara lain dokumentasi untuk mendukung penelitian, wawancara kepada pemilik perusahaan terkait pencarian informasi secara mendalam pada topik penelitian dan sumber tinjauan pustaka. Sedangkan data kuantitif di mengacu pada terjadinya coal plugging terjadi. Tahapan yang dilakukan pada penelitian sebagai berikut :

a Melakukan identifikasi top level event dengan syarat yang digunakan yaitu clearly, observable, un-ambigous definable dan measurable[29]-[31]. 
b. Membuat diagram pohon kesalahan dengan menunjukkan bagaimana top level event dapat muncul pada jaringan yang dibuat [12], [32], [33]

c. Penentuan minimal cut-set digunakan untuk mengkombinasikan penyebab munculnya top level event [34]

\section{Hasil dan Pembahasan}

Coal Plugging adalah kondisi terhentinya aliran batubara pada peralatan sistem coal feeder di karenakan penyumbatan batu bara yang basah atau menggumpal sehingga berdampak pada terganggunya proses penyaluran batubara menuju ruang pembakaran unit sistem tersebut.
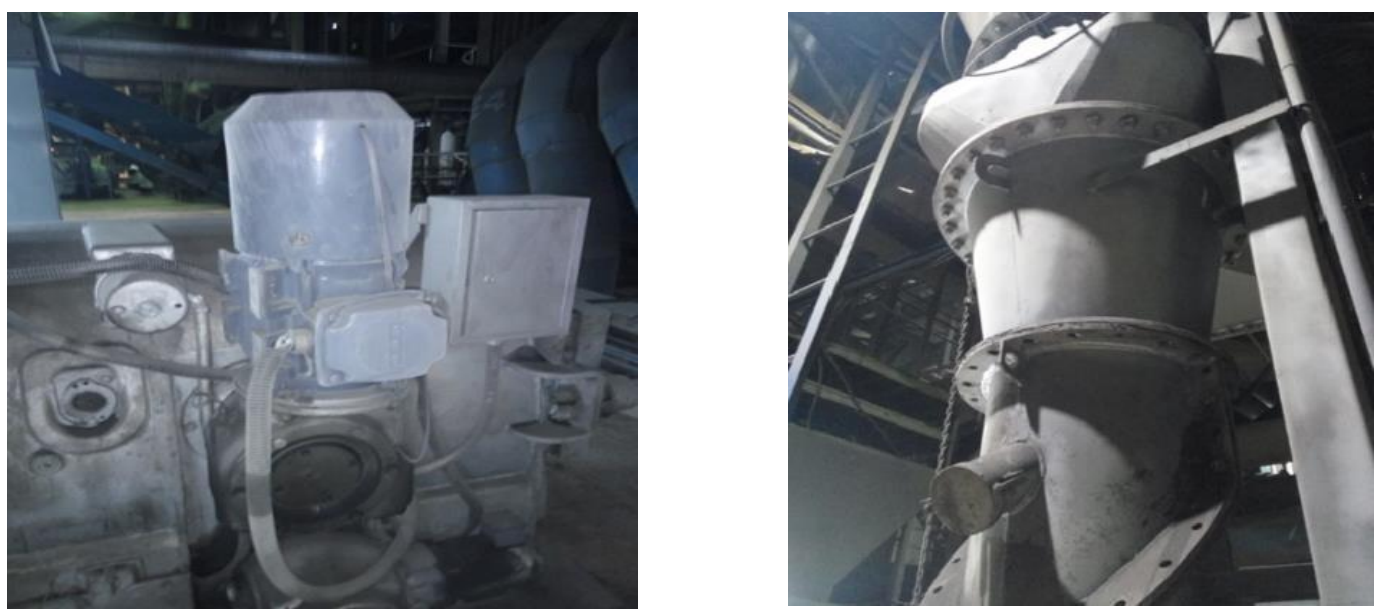

Gambar 3. Kondisi Saat Tidak Terjadi Plugging

Pada gambar 3, kondisi mesin saat tidak terjadi plugging. Terlihat kondisi komponen dan saluran bersih dari bekas ataupun gumpalan batu bara. Kondisi tersebut membuat mesin dapat bekerja sesuai kinerja yang diberikan dan diatur oleh sumber daya manusianya. Kondisi yang timbul akibat adanya coal plugging dapat menyumbat aliran sistem coal feeder. Terjadinya penyumbatan karena batu bara tersebut tidak dapat memasuki saluran sistem, dikarenakan volume yang terlalu besar dan dapat merusak aliran sistem coal feeder tersebut. Terjadinya coal plugging dengan gambar sebagai berikut :

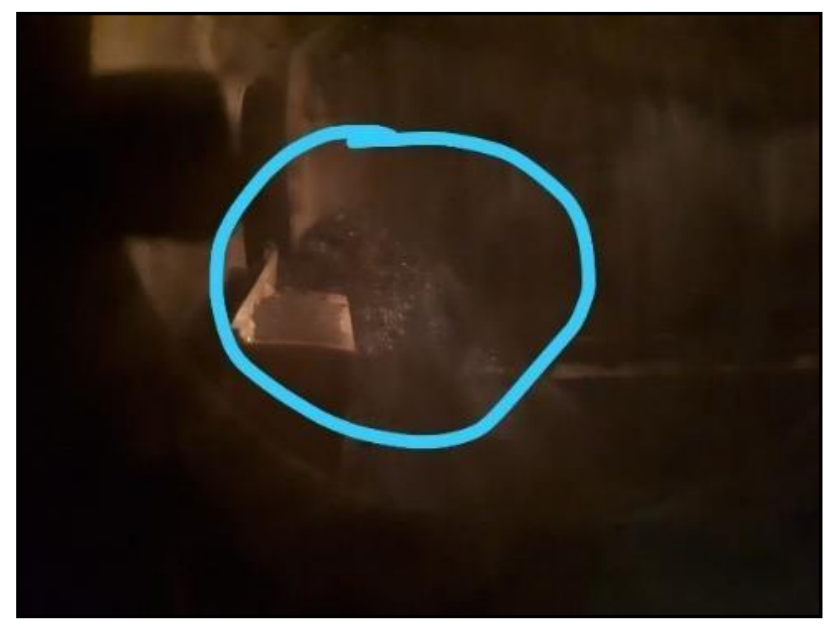

Gambar 4. Kondisi Terjadinya Coal Plugging

Pada gambar 4, adalah terjadinya coal plugging. Disini kondisi serpihan batu bara memasuki ruang aliran dan lambat laun akan menyubat aliran tersebut. Oleh sebab itu, 
dilakukan analisis menggunakan FTA (Failure Mode and Effect Analysis) dengan hasil sebagai berikut :

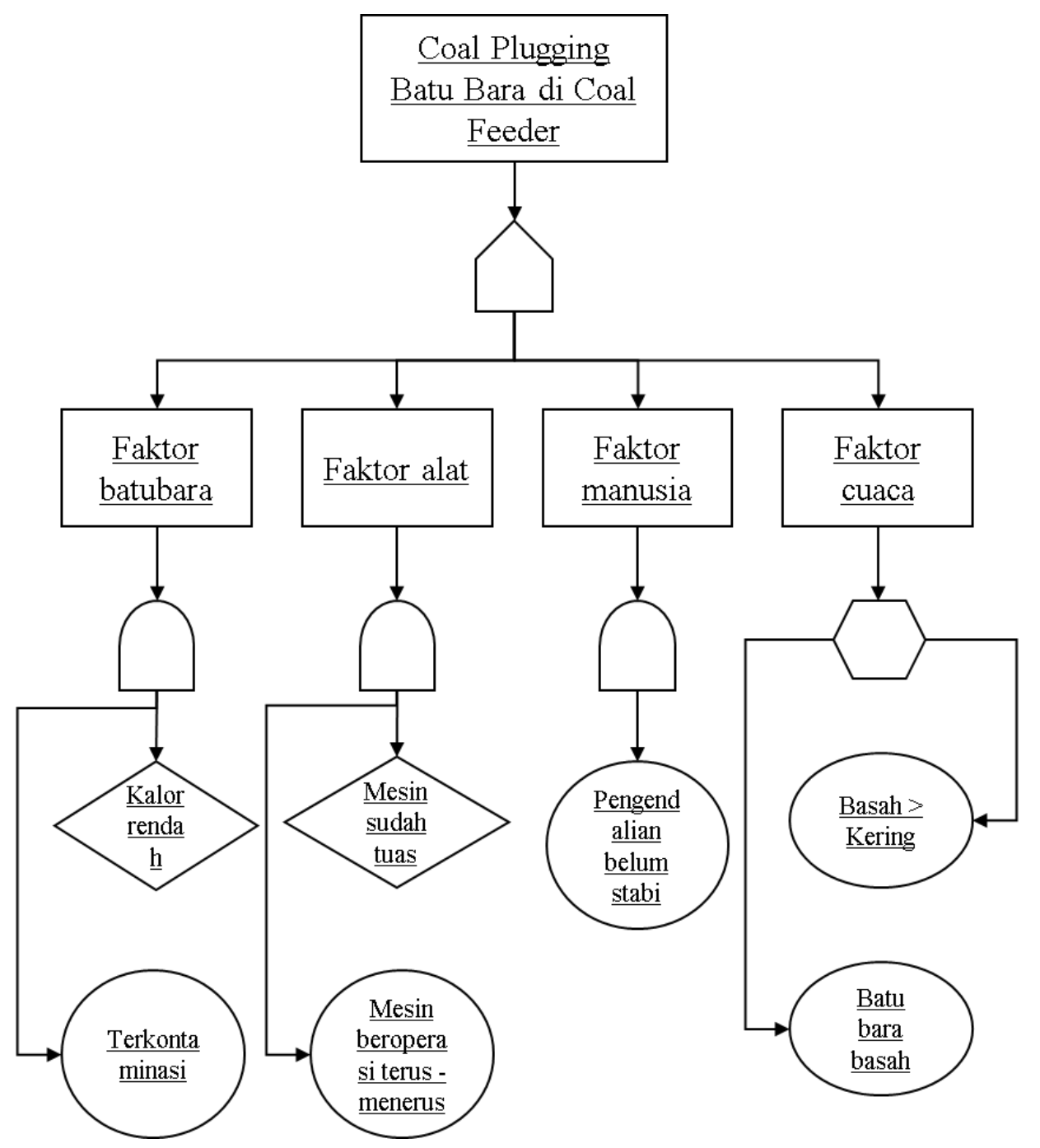

Gambar 5. Diagram FTA (Fault Tree Analysis) Coal Plugging di Coal Feeder

Tabel $1.5 \mathrm{~W}+1 \mathrm{H}$

\begin{tabular}{|c|c|c|c|c|c|}
\hline What & Why & Who & When & Where & How \\
\hline $\begin{array}{l}\text { Faktor alat } \\
\text { (mesin) }\end{array}$ & $\begin{array}{l}\text { Mesin beroperasi } \\
\text { terus - menerus } \\
\text { dan kondisi mesin } \\
\text { sudah tua }\end{array}$ & $\begin{array}{l}\text { Operator dan } \\
\text { manager }\end{array}$ & 2020 & $\begin{array}{l}\text { Coal } \\
\text { feeder } \\
\text { dan } \\
\text { pulver } \\
\text { izer }\end{array}$ & $\begin{array}{l}\text { Melakukan analisa } \\
\text { penggunaan mesin agar } \\
\text { tidak beroperasi terus- } \\
\text { menerus dan melakukan } \\
\text { penggantian secepatnya } \\
\text { mesin yang sudah tua } \\
\text { tersebut agar operasi } \\
\text { dapat berjalan dengan } \\
\text { optimal } \\
\text { kembali }\end{array}$ \\
\hline $\begin{array}{l}\text { Faktor } \\
\text { manusia }\end{array}$ & $\begin{array}{l}\text { Kurang kontrol } \\
\text { (pengawasan dan } \\
\text { pengecekan yang }\end{array}$ & $\begin{array}{l}\text { Supervisor dan } \\
\text { manager }\end{array}$ & 2020 & $\begin{array}{l}\text { Coal } \\
\text { Handl } \\
\text { ing }\end{array}$ & $\begin{array}{l}\text { Melakukan perubahan man } \\
\text { power schedule agar } \\
\text { lebih efektif dan } \\
\text { membuat }\end{array}$ \\
\hline
\end{tabular}




\begin{tabular}{|l|l|l|l|l|l|}
\hline & $\begin{array}{l}\text { kurang terhadap } \\
\text { mesin saat } \\
\text { supplybatu bara } \\
\text { menuju unit) }\end{array}$ & & & system & $\begin{array}{l}\text { laporan harian terkait } \\
\text { kegiatan pengawasan dan } \\
\text { pengecekan. }\end{array}$ \\
\hline $\begin{array}{l}\text { Faktor } \\
\text { material } \\
\text { batu } \\
\text { bara }\end{array}$ & $\begin{array}{l}\text { Kontaminasi akibat } \\
\text { terkena paparan } \\
\text { cuaca, hujan dan } \\
\text { material lain serta } \\
\text { nilai kalori yang } \\
\text { rendah dari } \\
\text { batubara yang } \\
\text { digunakan saat ini. }\end{array}$ & Manager & 2020 & $\begin{array}{l}\text { Ruang } \\
\text { pemb- } \\
\text { akaran } \\
\text { Boiler }\end{array}$ & $\begin{array}{l}\text { Dengan memisahkan } \\
\text { batubara yang basahdengan } \\
\text { batubara yang kering secara } \\
\text { otomatis dengan } \\
\text { menggunakan alat coal } \\
\text { online analyzer (cna) dan } \\
\text { melakukan evaluasi terhadap } \\
\text { supplier batubara saat ini }\end{array}$ \\
\hline $\begin{array}{l}\text { Faktor } \\
\text { cuaca } \\
\text { (lingku } \\
\text { ngan) }\end{array}$ & $\begin{array}{l}\text { Batu bara basah } \\
\text { diakibatkan oleh } \\
\text { hujan }\end{array}$ & Manager & 2020 & $\begin{array}{l}\text { Coal } \\
\text { stock } \\
\text { area }\end{array}$ & $\begin{array}{l}\text { Membuat penutup atau cover } \\
\text { penyimpanan batubara dari } \\
\text { hujan }\end{array}$ \\
\hline
\end{tabular}

Sumber : Olahdata, 2020

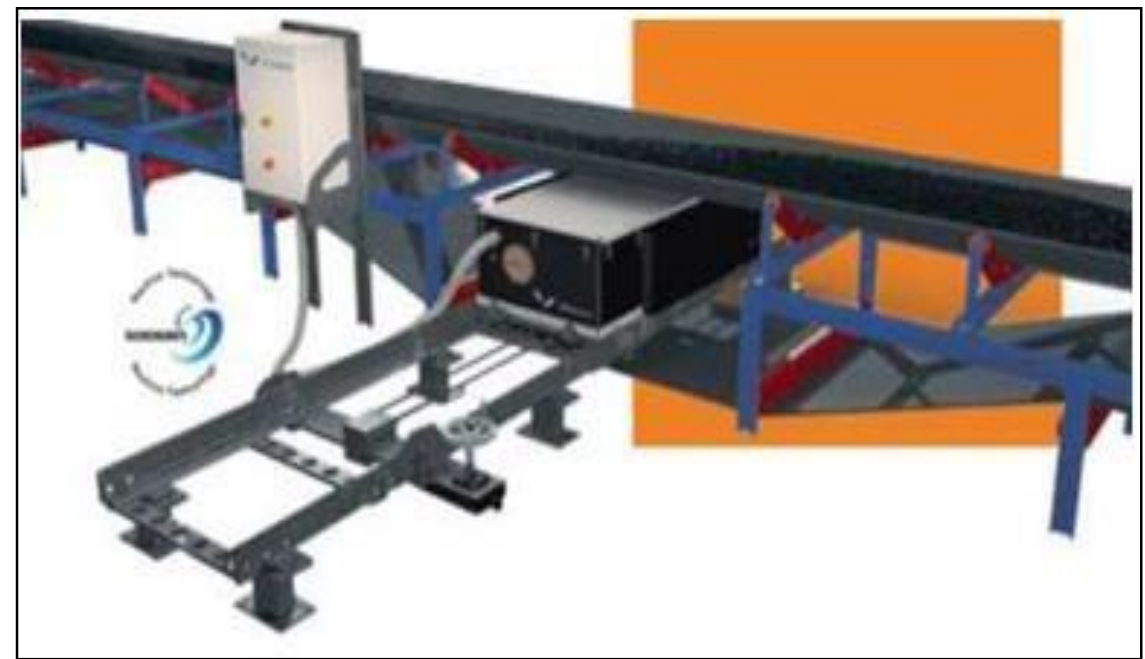

Gambar 6. Coal Online Analyzer

Alat Coal Online Analyzer (CNA) ini dapat memberikan informasi dan pencegahan secara realtime untuk komposisi unsur kimia, nilai kalor, kandungan abu, zat melayang dan batubara basah atau menggumpal. Teknologi pembangkitan neutron CNAmemungkinkan untuk memisahkan apabila kondisi batu bara dalam keadaan menggumpal dengan cara mendeteksisecara otomatis.

\section{Kesimpulan dan Saran}

Berdasarkan uraian-uraian yang telah dikemukakan sebelumnya makadapat ditarik kesimpulan sebagai berikut: Penyebab coal plugging atau penyumbatanyang terjadipadamesincoal feeder disebabkan oleh adanya kontaminasi pada batubara yang digunakan, nilai kalori batubara yang rendah, mesin beroperasi secara terus menerus, mesin sudah tua, kurangnya kontrol dari pihak pekerja dan batubara basah saat akan digunakan. Usulan perbaikan telah dibuat untuk mengurangi bahkan menghilangkan risiko yang terjadi pada mesin cold feeder setelah dilakukan FTA dan salah satunya adalah dengan 
cara memisahkan batubara basah dengan batubara yang kering secara otomatis menggunakan alat coal online analyzer. Saran yang diberikan untuk penelitian ini adalah diperlukan penggunaan metode Failure Mode and Effect Analysis. Untuk pembaca dapat digunakan sebagai referensi untuk penerapan penelitian ini.

\section{Daftar Pustaka}

[1] H. Jin, Y. Lu, B. Liao, L. Guo, and X. Zhang, "Hydrogen production by coal gasification in supercritical water with a fluidized bed reactor," in International Journal of Hydrogen Energy, 2010.

[2] B. F. Towler, M. Firouzi, H.-G. Holl, R. Gandhi, and A. Thomas, "Field Trials of Plugging Oil and Gas Wells with Hydrated Bentonite," 2016.

[3] N. Nurhalim, R. B. Cahyono, and M. Hidayat, "Karakteristik Bio-Briket Berbahan Baku Batu Bara dan Batang/Ampas Tebu terhadap Kualitas dan Laju Pembakaran,” J. Rekayasa Proses, 2018.

[4] Anggads, "Boiler sebagai Pemanas Air," blogspot.com, 2016. [Online]. Available: http://anggadds.blogspot.com/p/pengertian-boiler-boiler-merupakan.html. [Accessed: 15-Jan-2020].

[5] P. Paiton, P. T. Ytl, L. Kristianingsih, and A. S. Proses, "Analisis Safety System dan Manajemen Risiko pada Steam Boiler PLTU di Unit 5,” J. Tek. POMITS, 2013.

[6] Insinyoer, "Prinsip Kerja Boiler," Insinyoer.com, 2018. [Online]. Available: http://www.insinyoer.com/prinsip-kerja-boiler/. [Accessed: 16-Jan-2020].

[7] Sugiharto and Agus, "Tinjauan Teknis pengoperasian dan Pemeliharaan Boiler," Forum Teknol., 2016.

[8] J. Ignac-Nowicka and T. Krenický, "Fault Tree Analysis as a Tool to Increase the Level of Security in an Enterprise," Multidiscip. Asp. Prod. Eng., vol. 1, no. 1, pp. 719-725, 2018.

[9] E. E. Hurdle, L. M. Bartlett, and J. D. Andrews, "System fault diagnostics using fault tree analysis," Proc. Inst. Mech. Eng. Part O J. Risk Reliab., vol. 221, no. 1, pp. 43$55,2007$.

[10] A. A. Baig, R. Ruzli, and A. B. Buang, "Reliability Analysis Using Fault Tree Analysis: A Review,” Int. J. Chem. Eng. Appl., vol. 4, no. 3, pp. 169-173, 2013.

[11] C. Vianello, M. A. Zanini, C. Pellegrino, and G. Maschio, "Probabilistic fault tree analysis of refinery plant components subject to earthquake scenarios," Chem. Eng. Trans., vol. 53, pp. 97-102, 2016.

[12] I. Akgün, F. Gümüşbuğa, and B. Tansel, "Risk based facility location by using fault tree analysis in disaster management," Omega (United Kingdom), vol. 52, pp. 168$179,2015$.

[13] D. F. Mayangsari, H. Adianto, and Y. Yuniati, "Usulan Pengendalian Kualitas Produk Isolator Dengan Metode Failure Mode and Effect Analysis (Fmea) Dan Fault Tree Analysis (Fta)," Tek. Ind. Nas. Bandung, vol. 3, no. 2, pp. 81-91, 2015. 
[14] T. Novianti, "Pemodelan Risiko Pendapatan Proyek Infrastruktur Jalan Tol dengan Pendekatan Fault Tree Analysis," vol. 6, no. 2, pp. 138-149, 2011.

[15] E. Nugraha and R. M. Sari, "Analisis Defect dengan Metode Fault Tree Analysis dan Failure Mode Effect Analysis," Organum J. Saintifik Manaj. dan Akunt., vol. 2, no. 2, pp. 62-72, 2019.

[16] M. T. Hidayat and R. Rochmoeljati, "Perbaikan Kualitas Produk Roti Tawar Gandeng Dengan Metode Fault Tree Analysis ( FTA ) Dan Failure Mode And Effect Analysis ( FMEA ) Di Pt . XXZ," Juminten J. Manaj. Ind. dan Teknol., vol. 01, no. 04, pp. 70$80,2020$.

[17] B. H. Kurniawan, M. Yusuf, and C. I. Parwati, "Evaluasi Perawatan Mesin Dengan Metode Fault Tree Analysis (FTA) dan Failure Mode And Effect Analysis (FMEA) pada Cv. Julang Marching," J. REKAVASI, vol. 4, no. 2, pp. 60-118, 2016.

[18] S. Mangengre, "Implementasi Metode Fault Tree Analysis Untuk Analisis Kecacatan Produk," J. Ind. Eng. Manag., vol. 4, no. 1, p. 47, 2019.

[19] N. R. Anugrah, L. Fitria, and A. Desrianty, "Usulan Perbaikan Kualitas Produk Menggunakan Metode Fault Tree Analysis (FTA) Dan Failure Mode and Effect Analysis," Reka Integr., pp. 146-157, 2019.

[20] S. Kabir, "An overview of fault tree analysis and its application in model based dependability analysis," Expert Syst. Appl., vol. 77, pp. 114-135, 2017.

[21] D. Z. Julianti, S. N. W. Pramono, and T. K. Tifani, “... Dan Barrier Analysis Untuk Membangun Daya Saing Produk Susu Sapi Melalui Peningkatan Capaian Persyaratan Mutu Sni ...," Pros. Semin. Nas. Pakar, pp. 0-7, 2019.

[22] N. S. Bhangu and S. Grover, "Application of fault tree analysis for evaluating reliability: A case study of gear box of wind turbine," Int. J. Adv. Sci. Technol., vol. 29, no. 3, pp. 4486-4492, 2020.

[23] A. Y. Kristanto and R. Rumita, "Analisis Penyebab Cacat Kain Dengan Menggunakan Metode Failure Mode and Effect Analysis (Fmea) Dan Fault Tree Analysis (Fta)," vol. 5, no. 1, pp. 1-8, 2016.

[24] N. P. Lestari, S. Syamsiah, and W. Budhijanto, "Evaluasi Kehandalan Reaktor Biogas Skala Rumah Tangga di Daerah Istimewa Yogyakarta dengan Metode Analisis Fault Tree," Eval. Kehandalan Reakt. Biogas Skala Rumah Tangga di Drh. Istimewa Yogyakarta dengan Metod. Anal. Fault Tree, vol. 10, no. 1, pp. 1-9, 2016.

[25] A. F. Mustika, M. H. Hasyim, and S. El Unas, "Analisa Keterlambatan Proyek Menggunakan Fault Tree Analysis (Fta) (Studi Kasus Pada Proyek Pembangunan Gedung Program Studi Teknik Industri Tahap II Universitas Brawijaya Malang)," J. Mhs. Jur. Tek. Sipil Univ. Brawijaya, vol. 1, no. 2, 2014.

[26] K. Naga, S. Ananth, V. Rakesh, and P. K. Visweswarao, "Design and Selecting the Proper Conveyor-Belt," Int. J. Adv. Eng. Technol. E, 2013.

[27] L. Zhao and Y. Lin, "Typical failure analysis and processing of belt conveyor," in Procedia Engineering, 2011.

[28] Moh. Nazir, "Metode Penelitian," Metod. Penelit., 2014. 
[29] G. J. Leelipushpam, I. J. Jebadurai, and J. Jebadurai, "Fault Tree Analysis based Virtual Machine Migration for Fault-Tolerant Cloud Data Center," J. Integr. Des. Process Sci., vol. Preprint, pp. 1-17, 2019.

[30] Z. Hamza and S. Hacene, "Reliability and safety analysis using fault tree and Bayesian networks," Int. J. Comput. Aided Eng. Technol., vol. 11, no. 1, pp. 73-86, 2019.

[31] N. A. Wessiani and F. Yoshio, "Failure mode effect analysis and fault tree analysis as a combined methodology in risk management," $\{$ IOP $\}$ Conf. Ser. Mater. Sci. Eng., vol. 337, p. 12033, Apr. 2018.

[32] H. W. Li, Y. Ren, and L. N. Wang, "Research on Software Testing Technology Based on Fault Tree Analysis," Procedia Comput. Sci., vol. 154, pp. 754-758, 2018.

[33] X. Chen, H. Ren, and C. Bil, "Fault tree analysis for composite structural damages," Proc. Inst. Mech. Eng. Part G J. Aerosp. Eng., vol. 228, no. 9, pp. 1466-1474, Jul. 2013.

[34] P. Lacey, "An Application of Fault Tree Analysis to the Identification and Management of Risks in Government Funded Human Service Delivery," Proc. 2nd Int. Conf. Public Policy Soc. Sci. held Kuching, Oct. 31, 2011, pp. 1-15, 2011. 